\title{
Features of recording practices and communication during nursing handover: a cluster analysis*
}

\section{Características da gravação de práticas e comunicação durante a troca de turno de enfermagem: uma análise de grupo}

Características de la grabación de prácticas y comunicación durante el cambio de turno de enfermería: un análisis de grupo

Nikos Rikos ${ }^{1,2}$, Manolis Linardakis ${ }^{2}$, Michael Rovithis ${ }^{1}$, Anastas Philalithis ${ }^{2}$

How to cite this article:

Rikos N, Linardakis M, Rovithis M, Philalithis A. Features of recording practices and communication during nursing handover: a cluster analysis. Rev Esc Enferm USP. 2018;52:e03401. DOI: http://dx.doi.org/10.1590/S1980-220X2018006203401

* Extracted from thesis: "The assessment of the information of Nursing Handover in a hospital in Greece", University of Crete, Faculty of

Medicine, Department of Social Medicine, 2016.

${ }^{1}$ Technological Educational Institute of Crete, School of Health and Welfare Services, Department of Nursing, Heraklion, Greece.

${ }^{2}$ University of Crete, Faculty of Medicine, Department of Social Medicine, Heraklion, Greece.

\section{ABSTRACT}

Objective: To record and identify the characteristics of nursing handovers in a tertiary hospital. Method: Observational study. Twenty-two nurses participated in 11 nursing handovers in 2015/16, using a recorded audio system and an unstructured observation form. Hierarchical cluster analysis was performed. Results: Thirty characteristics were identified. The nursing handovers were based on the clinical status of patients, and all nurses obtained specialized scientific knowledge specific to the clinical environment. The information used was not based on nursing diagnoses and not in accordance with best nursing clinical practice. The following four clusters emerged among the 30 characteristics: 1) the use of evidence-based nursing practice, 2) the nonuse of evidencebased nursing practice and its correlation with strained psychological environment, 3) patient management and the clinical skills/knowledge of nurses, and 4) handover content, quality of information transferred and specialization. Conclusion: Multiple characteristics were observed. The majority of characteristics were grouped based on common features, and 4 main clusters emerged. The investigation and understanding of structural relations between these characteristics and their respective clusters may lead to an improvement in the quality of nursing health care services.

\section{DESCRIPTORS}

Patient Handoff; Nursing Care; Nursing Audits; Nursing Services. 


\section{INTRODUCTION}

The nursing handover is a process that has been carried out in almost all hospital nursing departments for decades. The nursing handover is defined as the transfer of necessary information between nurses at the change of shifts, together with the relevant authority, accountability and responsibility ${ }^{(1)}$. The aim of the nursing handover is the transfer of relevant and essential information ensuring the continuity of quality patient care. However, there is no consensus by researchers and academics on what this process should include, although the literature recommends various data presentation models $s^{(2)}$. Furthermore, there are opposing views on whether there should be a "full transfer" of responsibility during a handover. Some staff members report from the moment the handover is made, while others report after its conclusion or from the actual start of care interventions ${ }^{(3)}$. These differing views are due to both the personal and the professional commitment of the staff to the welfare and care of patients ${ }^{(3)}$. Nursing handovers comprise a wide variety of subjects, problems and processes. Researchers, clinical nurses, physicians and hospital administrations consider nursing handovers to be a significant factor leading to the assurance of consistency and provision of quality patient care ${ }^{(4)}$. The content of nursing handovers is complex and multifaceted, as it includes communication among nurses, communication among attendants, patients and other health care professionals and provides techniques and "tools" with the aim of providing quality patient care. Moreover, nursing handovers between every work shift are not only multifaceted but also inextricably linked to the human factor, which defines and reconstructs the structural elements of the procedure itself in issues regarding behavior and interpersonal relationships between colleagues ${ }^{(5)}$.

The primary aim determining the context of every nursing handover is preserving the safety and consistency of nursing care. The nursing handover includes entering notes in the nursing folder and patient nursing diagrams, organizing how patient problems are managed and handled, and the dissemination of information, orally or in writing, ensuring constant, holistic and quality health care. Official bodies recommend that clinical handovers should also include a written (original) form to be filled out face-to-face in the oral handover method ${ }^{(6)}$. In addition, related studies suggest that the standardized transfer of information will potentially improve the efficacy of the nursing hando$\operatorname{ver}^{(7-8)}$. Nursing handovers contain important quality information on the nursing care of patients, promoting the continuity of care, the achievement of therapeutic aims and the improvement of patient health ${ }^{(9)}$. Furthermore, nursing handovers include educational and sociocultural elements and involve the planning and organization of the care provided, leading to teamwork and solidarity among colleagues. An information-poor handover has a negative impact on patient health outcomes ${ }^{(10)}$. Thus, it is of great interest to broaden our research knowledge concerning nursing handovers and their characteristics to provide a deeper understanding of issues related to the quality of care in hospitals.

The aim of the present study was to record and identify the characteristics of nursing handovers in the environment of health care provision. A further objective was to investigate differences and similarities in the characteristics of nursing handovers.

\section{METHOD}

This observational study was conducted at the University General Hospital of Heraklion in Crete, Greece, from November 2015 to February 2016. The sampling framework and field of study consisted of eleven clinics out of the twenty-seven clinics chosen by the stratified random sample design; the clinics that were included in the study represent the entire spectrum of medical and nursing care offered by a university hospital in Greece (internal medicine, surgical, pediatrics). Specialist departments were excluded, such as the Intensive Care Unit (ICU) and the psychiatric clinic, due to the specialized care that they offer. After those exclusions, twenty-two clinics remained, following the official hospital organization chart. Half of these clinics were randomly selected, resulting in the following eleven clinics: a) the first five clinics of the internal medicine section, $b$ ) the first three clinics of the surgery section, and c) the three clinics of the pediatrics section. Each of the clinics under study employs 6 nurses with a bachelor's degree. The average number of patients is 45 per clinic. The sample originally consisted of 11 oral and written nursing handovers by 22 nurses ( 3 males/19 females, mean age $39.3 \pm 8.2$ years) who worked shifts on a specific day in the nursing departments and were included in the study based on the hospital shift schedule. The day was chosen according to the hospital duty schedule. The day on which the hospital was on general duty was selected due to the increased traffic and the diversity of cases. The study was based on the time the shift was handed over and received; thus, all nurses had an equal chance of being outgoing or incoming.

Unstructured observation by the researcher, together with a recording audio system, was employed to collect the data in the nurses' office in the eleven clinics; this method facilitates the observation of behaviors, interaction, communication and characteristics, such as the quality of the information transferred and the creation of action plans to ensure the effective nursing management of patients ${ }^{(11)}$. In the present study, the researcher, having informed the participants and obtained their written permission before the observation, allowed the participants to choose where the handover would take place and wrote down the data and information arising during the handover. The data were personally gathered by the researcher, who did not participate in the process in any way. He was placed in a spot where the participants were not in direct visual contact with him, from which he conducted the unstructured observation of written and oral handovers using a recording audio system and the researcher's own handwritten notes, which he did not communicate to the participants at any point during the observation process. The entire process took an estimated 25 minutes.

Ethical approval was obtained from the Research and Bioethics committee of the University Hospital of Heraklion (Crete, Greece) reference number 2129 (March 23rd, 2010). The participants enrolled in the study were informed about the study objectives, expected outcomes and associated benefits and risks. Written consent was received from the participants before they were observed and recorded. In addition, permission to use the hospital facilities was obtained by the author prior to the data collection. 
Data were analyzed using SPSS software (IBM SPSS Statistics for Windows, Version 24.0. Armonk, NY: IBM Corp). The frequencies of the characteristics were estimated based on the clinic and/or department categorization. Binomial and chi-square $\left(\chi^{2}\right)$ tests and $95 \%$ confidence intervals $(95 \% \mathrm{CIs})$ were used to compare responses. A hierarchical cluster analysis was performed to identify relative and homogeneous factor groups ${ }^{(12-13)}$. This method allowed the classification of the characteristics in groups as well as between clinics based upon similar features, such as common behaviors during job procedures. Ward's method was used to assess the Euclidean distance of binary data. A total of thirty characteristics were identified by two independent researchers in the study to ensure credibility. The analysis was performed by both researchers working both separately and jointly. The field notes were placed into a table to systematically analyze the context of the report. The characteristics were finalized following full agreement between the two researchers, and the intercoder agreement was $\mathrm{k}=0.91$. Finally, the coders discussed their differences and reached a consensus.

\section{RESULTS}

Twenty-two nurses with tertiary education participated in the study, of whom $n=19(86.4 \%)$ were female. The mean age was $39.3 \pm 8.2$ years, and $n=17(77.3 \%)$ were registered nurses. While the mean length of service was 18.7 years, $n=10$ (45.5\%) had been working for more than 20 years (Table 1 ).

Table 1 - Characteristics of the 22 study participants - Heraklion, Greece, 2015-2016.

\begin{tabular}{lccc}
\hline & & N & $\%$ \\
\hline Gender & males & 3 & 13.6 \\
females & ypears & 19 & 86.4 \\
& $31-40$ & 4 & 18.2 \\
mean \pm standard deviation (min-max) & 8 & 36.4 \\
Profession & registered nurse & 17 & 45.5 \\
& staff or head nurse & 5 & $39.3 \pm 8.2(27-53)$ \\
Departments & Pediatric General (3 clinics) & 6 & 27.3 \\
& Surgical (3 clinics) & 6 & 27.3 \\
Occupation & Internal Medicine (5 clinics) & 10 & 27.3 \\
status, years & mean \pm standard deviation & & 45.4 \\
& (min-max) & $10.7 \pm 6.9(5-30)$ \\
\hline
\end{tabular}

Thirty different characteristics of nursing handover methods were identified. Six clinics (54.5\%) used a combination of an electronic recording system and nursing folders, four clinics (36.4\%) used the nursing folders supplemented with personal notes, and one clinic used personal notes only, which is an outdated practice (Table 2). The handovers exhibited a high frequency of common characteristics, as follows: all (100\%) were based on the detailed clinical status of the patients, seven
(63.6\%) started from the first day of hospitalization up to that time, and $100 \%$ included further information provided by other health professionals, primarily doctors. All of the nurses (100\%) believe that they had specialized scientific knowledge specific to the clinical environment rather than general scientific knowledge and, finally, $100 \%$ of the nurses appeared to base their actions particularly on empirical skills and knowledge acquired during the course of their work. Nine of the nurses (81.8\%) reported that they work in a strained working environment, while eight nurses (72.7\%) appeared to employ a substantial biopsychosocial approach and participate in the interdisciplinary management of the patients and their environment. It was noted that the information used in the nursing handovers was not based upon nursing diagnoses and was not in accordance with best nursing clinical practice in nine (81.8\%) cases. Particular mention should be made of the fact that only two of the 11 clinics used information based only on the scientific data with evidence-based documentation, and only one clinic implemented a nursing clinical examination.

Table 2 - Frequency of the characteristics in the 11 clinics of the University Hospital in Crete - Heraklion, Greece, 2015-2016.

\begin{tabular}{|c|c|c|}
\hline Characteristics & $\mathbf{n}$ & $\%$ \\
\hline 1. Based on the patient's clinical status & 11 & 100.0 \\
\hline $\begin{array}{l}\text { 2. The handover is simply and scientifically approached } \\
\text { without the evidence-based nursing documentation }\end{array}$ & 8 & 72.7 \\
\hline 3. Nurses act with special skills and comments & 8 & 72.7 \\
\hline 4. All nursing levels participate & 9 & 81.8 \\
\hline 5. Key management by nurses & 8 & 72.7 \\
\hline $\begin{array}{l}\text { 6. Participation in the interdisciplinary management of the } \\
\text { patients }\end{array}$ & 8 & 72.7 \\
\hline 7. Further information from other health professionals & 11 & 100.0 \\
\hline 8. Substantial biopsychosocial approach & 8 & 72.7 \\
\hline 9. Strong emotional bonding with the patients & 5 & 45.5 \\
\hline 10. Not based upon nursing diagnoses & 9 & 81.8 \\
\hline 11. Not acting according to the Best Nursing Clinical Practice & 9 & 81.8 \\
\hline 12. Handle with Nursing Diagnoses & 2 & 18.2 \\
\hline 13. Management according to the Best Nursing Clinical Practice & 2 & 18.2 \\
\hline 14. Starting from the first day of hospitalization up to that time & 7 & 63.6 \\
\hline $\begin{array}{l}\text { 15. Special scientific knowledge specializing in the } \\
\text { clinical environment }\end{array}$ & 11 & 100.0 \\
\hline 16. Considerably detailed handover & 9 & 81.8 \\
\hline 17. Strained working environment & 9 & 81.8 \\
\hline 18. Strained psychological environment & 7 & 63.6 \\
\hline $\begin{array}{l}\text { 19. It is noticed that nurses perform and act independently, } \\
\text { regardless of their instructions }\end{array}$ & 5 & 45.5 \\
\hline 20. Act auxiliary to other health professionals & 10 & 90.9 \\
\hline 21. Patient education or training & 10 & 90.9 \\
\hline 22. Use of scientific terminology & 9 & 81.8 \\
\hline $\begin{array}{l}\text { 23. Satisfactory general scientific knowledge beyond the } \\
\text { Nursing Science }\end{array}$ & 6 & 54.5 \\
\hline 24. Use of empirical skills & 11 & 100.0 \\
\hline 25. Implementation of specialized skills and interventions & 6 & 54.5 \\
\hline $\begin{array}{l}\text { 26. Based only on the scientific data with evidence-based } \\
\text { documentation character }\end{array}$ & 2 & 18.2 \\
\hline 27. Implementation of Nursing clinical examination & 1 & 9.1 \\
\hline 28. Use of electronic recording system \& Nursing folders & 6 & 54.5 \\
\hline 29. Use of Nursing folders only, in a hardcopy form & 1 & 9.1 \\
\hline 30. Use of Nursing folders in a hardcopy form and notes & 4 & 36.4 \\
\hline
\end{tabular}


In grouping the data based on the three departments of the clinics studied (Table 3), it was observed that in the pediatric department, the nursing handover was based entirely (100\%) on the patients' general clinical condition. Although the nurses have specific skills and targeted observations, they do not operate on the basis of clinical diagnoses or best clinical practice but rather on their empirical knowledge and skills acquired during the course of their work. Moreover, the nurses do not formulate patient management plans independently of medical instructions. Another striking characteristic is the strong emotional bonding with and very good biopsychosocial approach to younger patients. The surgical department presented characteristics distinct from the other two departments. No special skills or targeted observations were noted, and nurses did not employ a biopsychosocial approach to patients, thus reducing their holistic management and participation in the education of the patients. However, nursing handovers operated more independently and were not solely based on the application of medical instructions by the physicians, while they also appeared to apply specialized interventions. In the internal medicine department, the most important finding was that, even in a low proportion of cases (40\%), the handovers appeared to operate on the basis of nursing diagnoses, while patient care plans were also based on best nursing clinical practice. Finally, regarding recording methods, the pediatric and surgical departments favored the electronic method combined with nursing folders (66.7\%), while the internal medicine department used a combination of nursing folders and personal notes (60\%).

Table 3 - Frequency of the characteristics between the three departments of University Hospital in Crete - Heraklion, Greece, 2015-2016.

\begin{tabular}{|c|c|c|c|}
\hline \multirow{2}{*}{ Characteristics } & \multicolumn{3}{|c|}{ Departments } \\
\hline & Pediatric General & Surgical & Internal Medicine \\
\hline 1. Based on the patient's clinical status & 100.0 & 100.0 & 100.0 \\
\hline $\begin{array}{l}\text { 2. The handover is simply and scientifically approached without the evidence based } \\
\text { nursing documentation }\end{array}$ & 100.0 & 100.0 & 40.0 \\
\hline 3. Nurses act with special skills and comments & 100.0 & 33.3 & 80.0 \\
\hline 4. All nursing levels are participating & 66.7 & 100.0 & 80.0 \\
\hline 5. Key management by nurses & 66.7 & 100.0 & 60.0 \\
\hline 6. Participation in the interdisciplinary management of the patients & 66.7 & 100.0 & 60.0 \\
\hline 7. Further information from other health professionals & 100.0 & 100.0 & 100.0 \\
\hline 8. Substantial biopsychosocial approach & 100.0 & 33.3 & 80.0 \\
\hline 9. Strong emotional bonding with the patients & 100.0 & 0.0 & 40.0 \\
\hline 10. Not based upon nursing diagnoses & 100.0 & 100.0 & 60.0 \\
\hline 11. Not acting according to the Best Nursing Clinical Practice & 100.0 & 100.0 & 60.0 \\
\hline 12. Handle with Nursing Diagnoses & 0.0 & 0.0 & 40.0 \\
\hline 13. Management according to the Best Nursing Clinical Practice & 0.0 & 0.0 & 40.0 \\
\hline 14. Starting from the first day of hospitalization up to that time & 100.0 & 33.3 & 60.0 \\
\hline 15. Special scientific knowledge specializing in the clinical environment & 100.0 & 100.0 & 100.0 \\
\hline 16. Considerably detailed handover & 100.0 & 66.7 & 80.0 \\
\hline 17. Strained working environment & 100.0 & 66.7 & 80.0 \\
\hline 18. Strained psychological environment & 100.0 & 0.0 & 80.0 \\
\hline 19. It is noticed that nurses perform and act independently, regardless of 33.3 & & 66.7 & 40.0 \\
\hline 20. Act auxiliary to other health professionals & 100.0 & 100.0 & 80.0 \\
\hline 21. Patient education or training & 100.0 & 66.7 & 100.0 \\
\hline 22. Use of scientific terminology & 66.7 & 100.0 & 80.0 \\
\hline 23. Satisfactory general scientific knowledge beyond the Nursing Science & 0.0 & 66.7 & 80.0 \\
\hline 24. Use of empirical skills & 100.0 & 100.0 & 100.0 \\
\hline 25. Implementation of specialized skills and interventions & 33.3 & 66.7 & 60.0 \\
\hline 26. Based only on the scientific data with evidence-based documentation character & 0.0 & 0.0 & 40.0 \\
\hline 27. Implementation of Nursing clinical examination & 0.0 & 0.0 & 20.0 \\
\hline 28. Use of electronic recording system \& Nursing folders & 66.7 & 66.7 & 40.0 \\
\hline 29. Use of Nursing folders only, in a hardcopy form & 0.0 & 33.3 & 0.0 \\
\hline 30. Use of Nursing folders in a hardcopy form and notes & 33.3 & 0.0 & 60.0 \\
\hline
\end{tabular}

Across the 30 characteristics in all 11 clinics (results not shown in table/figure), a significantly higher proportion (64.2\%) received a positive response (i.e., yes) (binomial test, $\mathrm{p}<0.001$ ). However, there was no significant differentiation among the positive responses of the three departments $\left(\chi^{2}=1.207\right.$, d.f. $=2$, $\mathrm{p}=0.547)$. When the clinics were ranked in hierarchical order (Figure 1), a significant difference was observed between the positive responses of the pediatric and pulmonary clinics (76.7\%; $95 \% \mathrm{CI}, 60.1 \%$ to $90.0 \%)$ and those of the internal medicine clinic (40.0\%; 95\% CI, $23.3 \%$ to $56.7 \%)$. 


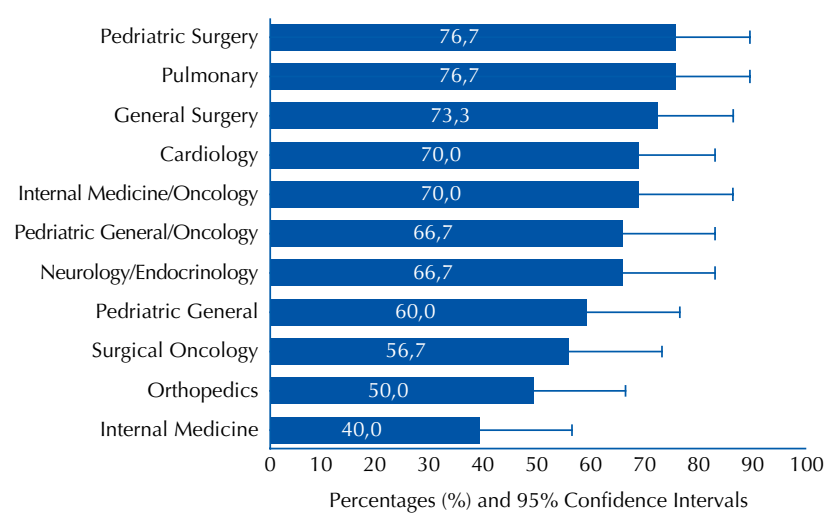

Figure 1 - Frequency of the characteristics in hierarchical order between the 11 clinics of the University Hospital in Crete - Heraklion, Greece, 2015-2016.
Based on the hierarchical cluster analysis, Figure 2 illustrates the various combinations of the 30 nursing characteristics. The following four main clusters emerged: 1 ) characteristics involving the use of evidence-based nursing practice (characteristics: 13 , $26,12,27,29$ and 30);2) characteristics involving the nonuse of evidence-based nursing practice and the correlation of such nonuse with a strained psychological environment (characteristics: 10,11, 29 and 18); 3) patient management and nurses' clinical skills and/or knowledge (characteristics: 19,25,5, 6, 4,23 and 28); and 4) handover content, quality of information transferred and specialization or otherwise of the nursing practices used (characteristics: 3, 8, 16, 14, 17, 21, 15, 24, 1, 7, 20 and 22). Figure 3, which combines the 30 characteristics among the 11 clinics, illustrates that three main groups with similar or common recording characteristics are formed. The first group contains the pediatric, oncology and cardiology clinics, the second group contains the orthopedic and internal medicine clinics, and the third group contains the neurology-endocrinology and pulmonary clinics.

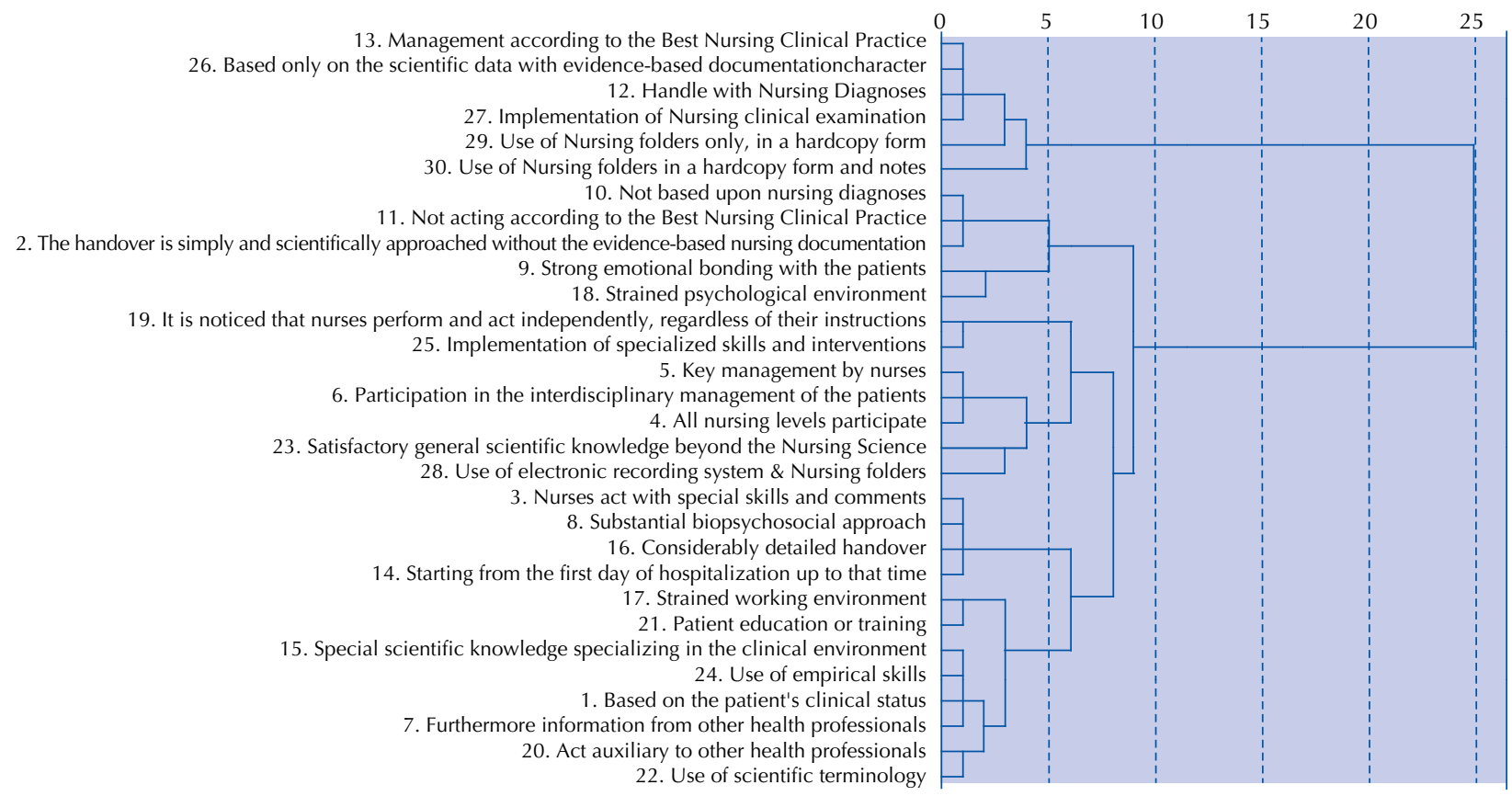

Figure 2 - Cluster analysis dendrogram of the 30 nursing characteristics in the 11 clinics of the University Hospital in Crete - Heraklion, Greece, 2015-2016.

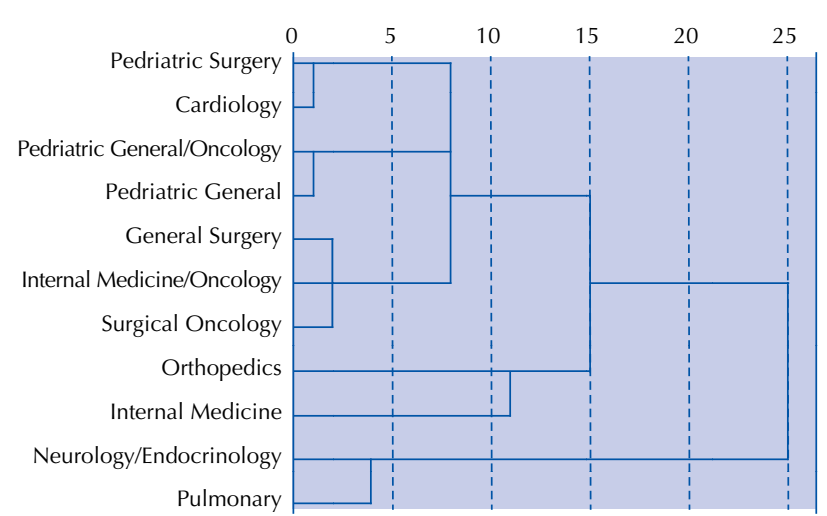

Figure 3 - Cluster analysis dendrogram of the 30 characteristics between the 11 Clinics of the University Hospital in Crete - Heraklion, Greece, 2015-2016.

\section{DISCUSSION}

The aim of the present study was to record and identify the characteristics of nursing handovers in the particularly difficult environment of tertiary health care provision. The primary nursing handover method was identified as the oral method combined with the use of electronic recording and handwritten notes by both nurses involved in each handover. Moreover, multiple characteristics were observed during the nursing handover procedures, but the majority of characteristics were found to have common features, and four main clusters emerged.

According to the literature, the oral handover at the shift change cannot be replaced by any other method because the handover is the only process in which the various aspects of 
nursing science and care can be identified and applied ${ }^{(14)}$. Other studies, in contrast, dispute the efficacy of the oral handover and consider it unnecessary because most of the information or practices discussed could be included in evidence-based nursing practice, rendering the oral handover unnecessarily time-consuming ${ }^{(15)}$. Printed forms, on the other hand, usually include clinical data on the patients, possibly in the form of reports, and questions regarding what occurred during the shift are answered, separately or in combination with other sources ${ }^{(16)}$. This method, combining oral and written handover, can also prevent the loss of vital information that could lead to increased negative outcomes, such as morbidity and fatality ${ }^{(15)}$. However, the oral method remains the most popular method of communication for shift change handovers ${ }^{(17)}$.

An additional characteristic observed in the present study was that the information on the clinical status of the patients comprised a large portion of the data collected during the nursing handovers. However, this information did not include data based on nursing diagnoses and therefore appeared not to operate on the basis of best nursing clinical practice. Effective nursing handover is only achievable through clearly defined clinical processes and, by extension, through the application of best nursing practices ${ }^{(8)}$. More effective clinical handovers can be achieved by clear processes regarding handover methods and the creation of a supportive work environment. Conversely, the absence of an official policy and organizational structure regarding clinical handovers is a well-known obstacle to their efficacy ${ }^{(8)}$. Most handovers approach patients as biological entities, focusing exclusively on responding to the various biological and clinical problems or the patients' needs and neglecting other aspects of nursing care.

Moreover, in the present study, no clear content structure characteristics were observed in the total data of nursing handovers because these were adapted according to the skills of the nurses. According to a previous study, the nursing handover is traditionally carried out as a conversation between the nurses away from the patient's room, thereby preventing patient participation; the same report claims that traditional nursing handovers often collect incomplete information due to the unsuitable, time-consuming and unstructured way in which they are applied ${ }^{(7)}$.

In the present study, the nursing staff, particularly in the internal medicine and surgical departments, appeared to possess particular skills, such as inserting catheters, independently administering solutions/pharmaceutical preparations for the immediate treatment of clinical events, using specialized materials and technical equipment, and making targeted observations for the timely handling of problems. Nonetheless, the staff did not operate on the basis of the clinical diagnoses and best clinical practice but rather on the empirical knowledge and skills acquired during the course of work. Moreover, the nurses did not draw up patient management plans independent of medical instructions, and the information transferred was not evidence-based but rather based primarily on the experience of the nurses. These characteristics also emerged as one of the four major groups of the cluster analysis. The nursing handover process provides the opportunity to reinforce the cohesion of the nurses as a group and the professional socialization, training, interaction and emotional support of group members ${ }^{(18-19)}$. Therefore, the handover must be precise, complete, specialized, relevant and, above all, based on objective criteria. However, transfers of information and responsibility that are inaccurate, incomplete and biased can lead to many errors and mistaken nursing practices, thereby increasing patient complications ${ }^{(20)}$. In the internal medicine and surgical departments, for example, the information exchanged during a handover is often inaccurate and influenced by the environment in which the handover takes place, making nurses feel that "there is something missing"(21). The guidelines on the handover contents focus on setting short-term and long-term objectives. The information, data and practices included therein should be both wide-ranging and quite specialized to meet the needs of the patients. Moreover, handovers should include information from other health care professionals, such as doctors, and nursing care should involve a holistic approach to patients (physical, psychosocial, intellectual) and their families ${ }^{(20)}$.

It is also important to note that, in the present study, strong emotional bonding as well as a very good biopsychosocial approach to younger patients was observed, but this was not the case with adult patients. Similar results have been reported in other studies showing that, in pediatric departments, the role of nurses and the families of young patients has changed ${ }^{(22)}$. Formerly, all responsibilities, interventions and care plan design were the job of professional nurses; now, however, the family or caregivers participate in full.

Another significant parameter that proved impossible to measure, due to its absence from the nursing handover practices observed in this study, was the execution of nursing handovers with the participation of the patient and their caregiver or relatives. In this study, the handovers took place in a specific nursing area, and in none of the clinics studied was it carried out at the patient's bedside or with the participation of the patient and/or their caregivers/relatives. A previous study $^{(23)}$ reported that when nursing handovers take place in offices or areas away from the patients, many patients feel that they are reduced to just numbers or medical diagnoses. Conversely, it has been observed that when family members are included in the handover, patients and their relatives feel safer and more accepting of the interventions taking place or the care plans to be applied, and they become more confident in the improvement of the patient's clinical status ${ }^{(24)}$.

Finally, the present study highlighted four basic groups of characteristics that share common or similar features. First, the use of evidence-based nursing practice was stressed. Nonuse of evidence-based nursing practice was also observed in conjunction with a stressful and strained working environment. Furthermore, practices emerged regarding patient management and nurses' clinical skills and/or knowledge. The final group involved practices connected with the handover content, the quality of information transferred and the specialization or otherwise of the nursing practices used. Although, according to the present state of knowledge, no similar grouping of nursing handovers has been identified in the literature, it is inferred that handover practices and the information and data they contain must be both wide-ranging and evidence-based to best meet patient needs. In a previous study, the main characteristics that 
emerged were that the information presented was based on nursing diagnoses and therefore appeared to operate on the basis of best nursing clinical practice ${ }^{(18)}$. The same study found that nurses used clinical handover. Additionally, other researchers identified the following three groups of characteristics: first, that not all information was based on nursing diagnoses; second, that the information transferred was not evidence-based; and third, that both knowledge and practices were primarily based on nurses' experience ${ }^{(25)}$.

\section{CONCLUSION}

In conclusion, multiple characteristics were observed during the nursing handover procedures. The majority of the characteristics were found to have common features, and four main clusters emerged. The first cluster of characteristics involved the use of evidence-based nursing practice, the second cluster involved nonuse of evidence-based nursing practice and the correlation with a strained psychological environment, the third cluster involved patient management and nurses' clinical skills and/or knowledge, and the fourth cluster involved the handover content, quality of information transferred and specialization or otherwise of the nursing practices used. The handovers exhibited a high frequency of common characteristics based on the patient's detailed clinical status, starting from the first day of hospitalization up to that time, and they included further information provided by other health professionals, primarily doctors. All observed nurses believed that they had specialized scientific knowledge specific to the clinical environment, rather than general scientific knowledge and, finally, nurses appeared to base their actions on empirical skills and knowledge acquired during the course of their work.
The nursing handover is a daily process observed at every level of health care, comprising the essential transmission of important information and the responsibility to apply best nursing practice. This process includes particular techniques and tools that contribute to communication among health professionals, patients and their families. With their complex and multifaceted content, nursing handovers are directly connected to the human factor, which determines their primary objective of preserving the safety and quality continuity of the health care provided. It is hoped that this study will provide nurses with a better understanding of the significance of the nursing handover and its role in health care safety and quality, encouraging nurses to change their implementation of the handover process and stimulating future research on the subject.

Our study investigated how this complex and vital procedure is structured and handled by the health care staff involved, taking into account an environment that is fraught with difficulties, such as the Greek health service today, in a country severely affected by a deep, long-term socioeconomic crisis. The Greek healthcare system is suffering from staff shortages, particularly nursing staff, and a lack of materials, technical infrastructure and specialized further education. Nevertheless, this healthcare system is managing to preserve a people-centered approach, overcoming any discrepancies regarding the quality application of nursing handovers and the aim of ensuring patient safety and the consistent quality of nursing care. The present study will also stimulate further research on this essential and multifaceted subject, creating a suitable environment for interventions to correct any errors, oversights or omissions and to reinforce existing strengths.

\section{RESUMO}

Objetivo: Gravar e identificar as características da troca de turno de enfermagem em um hospital terciário Método: Estudo observacional. Vinte e dois enfermeiros participaram de 11 trocas de turnos em 2015/16, usando um sistema de áudio gravado e um formulário de observação não estruturado. Foi realizada uma análise de grupo hierárquico. Resultados: Trinta características foram identificadas. As trocas de turno se basearam no estado clínico dos pacientes, e todos os enfermeiros obtiveram conhecimento científico especializado e específico para o ambiente clínico. A informação usada não se baseou nos diagnósticos de enfermagem e também não esteve de acordo com as melhores práticas clínicas de enfermagem. Os quatro grupos seguintes emergiram dentre as 30 características: 1) o uso de práticas de enfermagem baseadas em evidências, 2) o não uso de práticas de enfermagem baseadas em evidências e sua correlação com ambiente psicológico hostil, 3) manejo do paciente e habilidade/conhecimento dos enfermeiros e 4) conteúdo das trocas de turno, qualidade da informação transferida e especialização. Conclusão: Múltiplas características foram observadas. A maioria das características foram agrupadas com base nas características comuns e quatro grupos principais surgiram. A pesquisa e a compreensão das relações estruturais entre essas características e seus respectivos grupos podem levar a uma melhora da qualidade dos serviços de atendimento em saúde dos enfermeiros.

\section{DESCRITORES}

Transferência da Responsabilidade pelo Paciente; Cuidados de Enfermagem; Auditoria de Enfermagem; Serviços de Enfermagem.

\section{RESUMEN}

Objetivo: Grabar e identificar los rasgos del cambio de turno de enfermería en un hospital terciario. Método: Estudio observacional. Veintidós enfermeros participaron en 11 cambios de turno en 2015/16, utilizando un sistema de audio grabado y un formulario de observación no estructurado. Se llevó a cabo un análisis de grupo jerárquico. Resultados: Treinta características fueron identificadas. Los cambios de turno se basaron en el estado clínico de los pacientes, y todos los enfermeros lograron conocimiento científico especializado y específico para el entorno clínico. La información utilizada no estuvo basada en los diagnósticos de enfermería y tampoco estuvo en conformidad con las mejores prácticas clínicas de enfermería. Estos son los cuatro grupos siguientes que emergieron de las 30 características: 1) el uso de prácticas de enfermería basadas en evidencias, 2) el no uso de prácticas de enfermería basadas en evidencias y su correlación con el ambiente psicológico hostil, 3) manejo del paciente y habilidad/conocimiento de los enfermeros y 4) contenido de los cambios de turno, calidad de la información transferida y especialización. Conclusión: Múltiples rasgos fueron observados. La mayoría de las características se agruparon con base en las características comunes y cuatro grupos principales surgieron. La investigación y la comprensión de las relaciones estructurales entre dichas características y sus respectivos grupos pueden llevar a una mejora de la calidad de los servicios de atención en salud de los enfermeros.

\section{DESCRIPTORES}

Pase de Guardia; Atención de Enfermería; Auditoría de Enfermería; Servicios de Enfermería. 


\section{REFERENCES}

1. Kear TM. Patient handoffs: what they are and how they contribute to patient safety. Nephr Nurs J. 2016;43(4):339-42.

2. Johnson M, Jefferies D, Nicholls D. Exploring the structure and organization of information within nursing clinical handovers. Int J Nurs Pract. 2012;18(5):462-70.

3. Chin GS, Warren N, Kornman L, Cameron P. Transferring responsibility and accountability in maternity care: clinicians defining their boundaries of practice in relation to clinical handover. BMJ Open. 2012;2(5). pii: e000734. DOI: 10.1136/bmjopen-2011-000734

4. Buus N, Hoeck B, Hamilton BE. Nurses' shift reports: a systematic literature search and critical review of qualitative field studies. J Clin Nurs. 2016;26(19-20):2891-906.

5. Drach-Zahavy A, Hadid N. Nursing handovers as resilient points of care: linking handover strategies to treatment errors in the patient care in the following shift. J Adv Nurs. 2015;71(5):1135-45.

6. Australia. Government of South. Department of Health. Clinical Handover Guidelines [Internet]. Australia; 2013 [cited 2016 July 16]. Available from: http://www.sahealth.sa.gov.au/wps/wcm/connect/cd523300458ad11e9915dd519b2d33fa/guideline_clinical_handover_ oct2010_final.pdf?MOD=AJPERES

7. Klim S, Kelly AM, Kerr D, Wood S, McCann T. Developing a framework for nursing handover in the emergency department: an individualised and systematic approach. J Clin Nurs. 2013;22(15-16):2233-43.

8. Groves PS, Bunch JL, Cram E, Farag A, Manges K, Perkhounkova Y, Scott-Cawiezell J. Priming patient safety through nursing handoff communication: A simulation pilot study. West J Nurs Res. 2017;39(11):1394-411.

9. Foster S, Manser TT. The effects of patient handoff characteristics on subsequent care: a systematic review and areas for future research. Acad Med. 2012;87(8):1105-24.

10. Holly C, Poletick EB. A systematic review on the transfer of information during nurse transitions in care. J Clin Nurs. 2014;23(17-18):2387-96.

11. Carroll JS, Williams M, Gallivan TM. The ins and outs of change of shift handoffs between nurses: a communication challenge. BMJ Qual Saf. 2012;21(7):586-93

12. Everitt B, Landau S, Leese M, Stahl D. Cluster analysis. 5th ed. New York: Wiley; 2000.

13. Linardakis M, Papadaki A, Smpokos E, Micheli K, Vozikaki M, Philalithis A. Relationship of behavioral risk factors for chronic diseases and preventive health services utilization among adults, aged 50+, from eleven European countries. J Public Health (Germany). 2015;45(23):257-65.

14. Birmingham P, Buffum MD, Blegen MA, Lyndon A. Handoffs and patient safety: grasping the story and painting a full picture. West J Nurs Res. 2015;37(11):1458-78.

15. Johnson M, Cowin LS. Nurses discuss bedside handover and using written handover sheets. J Nurs Manag. 2013;21(1):121-9.

16. Mc Sweeney M, Landrigan C, Jiang H, Starmer A, Lightdale J. Answering questions on call: pediatric resident physicians' use of handoffs and other resources. J Hosp Med. 2013;8(6):328-33.

17. Kim M, Oh S. Assimilating to hierarchical culture: a grounded theory study on communication among clinical nurses. PLoS One. 2016;11:e0156305.

18. Blondon KS, Ehrler F, Godais SL, Wojtasikiewicz JY, Couderc C. approaches to improving nursing handoffs in surgical wards. Open J Nurs. 2017;7(9):1034-43.

19. Griffin T. Bringing change-of-shift report to the bedside: a patient- and family-centered approach. J Perinat Neonatal Nurs. 2010;24(4):348-53; quiz 54-5.

20. Mardis M, Davis J, Benningfield B, Elliott C, Youngstrom M, Nelson B, et al. Shift-to- shift handoff effects on patient safety and outcomes: a systematic review. Am J Med Qual. 2017;32(1):34-424.

21. Radtke K. Improving patient satisfaction with nursing communication using bedside shift report. Clin Nurse Spec. 2013 ;27(1):19-25.

22. Mikkelsen G, Frederiksen K. Family-centred care of children in hospital: a concept analysis. J Adv Nurs. 2011;67(5):1152-62.

23. Lu S, Kerr D, McKinlay L. Bedside nursing handover: patients' opinions. Int J Nurs Pract. 2014;20(5):451-9.

24. Tobiano G, Chaboyer W, McMurray A. Family members' perceptions of the nursing bedside handover. J Clin Nurs. 2013;22(1-2):192-200.

25. Kerr D, Lu S, McKinlay L, Fuller C. Examination of current handover practice: evidence to support changing the ritual. Int J Nurs Pract. 2011;17(4):342-50. 